\title{
Preschool Educators' Emotional Directions Towards Mathematics
}

\section{Lovisa Sumpter ${ }^{1}$ (D)}

Received: 15 August 2018 / Accepted: 4 September 2019 / Published online: 9 October 2019

(C) The Author(s) 2019

\begin{abstract}
This paper investigates Swedish preschool educators' emotional directions towards mathematics. A questionnaire was answered by 157 preschool educators and their responses were analysed using both quantitative and qualitative methods. The majority of preschool educators stated that they are positive towards mathematics. Regarding the hypotheses that education or years of experience have a positive impact on how you feel about a subject, the statistical analysis did not confirm these hypotheses. However, the results from the qualitative analysis suggest that some preschool educators change their feelings towards mathematics with time, experience, more education and/or new setting such as a new curriculum. They expressed a dynamic view where they previously have been more negative towards mathematics but now are much more positive. Some implications are that compared with the reputation, preschool educators express more positive feelings, and that targeted education is a contributing factor.
\end{abstract}

Keywords Affect $\cdot$ Educators $\cdot$ Emotional directions $\cdot$ Mathematics $\cdot$ Preschool

\section{Introduction}

A body of research has emphasised the important role of preschool educators' and primary teachers' affective world (e.g. conceptions, beliefs, attitudes) play for the practice of teaching (e.g. Einarsdottir, 2003; Greenes, 2004; Leavy, Hourigan \& Carroll, 2017; Lee \& Ginsburg, 2007; Spodek, 1987). It is through teachers' affective facets classroom practice will be planned and executed (van Oers, 2002; Philipp, 2007; Stipek \& Byler, 1997). Therefore, what preschool teachers think, feel and believe about mathematics and mathematics education play an important role for what happens in

Lovisa Sumpter

lovisa.sumpter@mnd.su.se

1 Department of Mathematics and Science Education, Stockholm University, SE-106 91

Stockholm, Sweden 
preschool. One conclusion is that children's attitudes towards mathematics will be influenced by their teachers since attitudes are results of experiences especially the interactions with parents and teachers (Gunderson, Ramirez, Levine \& Beilock, 2012). This has been stated to happen even in a longer perspective: that early caregivers' interaction has an influence for children's later achievement (Levine, Whealton Suriyakham, Rowe, Huttenlocher \& Gunderson, 2010).

Also, the correlation between affect and practice seems to be stronger with preschool teachers compared with primary school teachers (Ngan Ng, Lopez-Real \& Rao, 2003; Stipek \& Byler, 1997). Some researchers make the claim that the impact is greater than so: that female teachers that express strong emotions such as anxiety about mathematics transfer this negativity to girls, but not to boys, within a school year (Beilock, Gunderson, Ramirez \& Levine, 2010). In addition, preschool teachers are often described as lacking confidence teaching mathematics (Copley, 2004) and are generally portrayed as disliking mathematics trying to avoid to teach it (Ginsburg, Lee \& Boyd, 2008). Previous study reported that teachers with negative attitudes towards mathematics often teach for instrumental understanding, employing more rule-based, teacherdirected strategies than their peers with positive attitudes whose focus was on understanding, exploration and the discovery of mathematical relationships (Wilkins, 2008). Or, as Ball (1990) concluded, that teachers with strong negative feelings towards mathematics might not be an optimal starting point for teaching mathematics. If adding that this is people possibly responsible for the first interactions children have with the subject, one could conclude that the topic is rather important.

At the same time, this is a research area poorly understood: Benz's (2012) conclusion after reviewing research is that we still do not know enough about the mathematical affective world of people working in preschools. Most research focus on teachers' beliefs more than emotions (c.f. Philipp, 2007). This limited understanding of preschool teachers' emotions will diminish our ability to support in-service teachers but also students in teacher education (Thiel \& Jenssen, 2018). This is true in Sweden too especially when considering that this is a country where preschool teaching is very much a profession in change (Sheridan, Williams, Sandberg \& Vuorinen, 2011), although still differ with a focus on play instead of the trend of 'schoolification' that happen in a large part of the Western world (Sumpter \& Hedefalk, 2015; Waller, Sandeseter, Wyver, Ärlemalm-Hagsér \& Maynard, 2010). The aim here is to study Swedish preschool educators' emotional directions towards the subject. The research questions posed are as follows: (1) What main emotional directions towards mathematics do Swedish preschool educators express and what are the characteristics of these feelings regarding static and dynamic view? (2) What differences can be found in the emotional directions towards mathematics when comparing (a) educational background and (b) stated years of professional practice? Emotional direction is here main expressed directions such as positive, negative, neutral or mixed emotions, and static and dynamic view means either perceived fixed emotions or that it has changed. Preschool educator is a collective name for staff working in preschools with children in the age span 1-5. The first preschool curriculum that governs all preschools came in 1998, but recently it has been revised. The content is formulated as aims to strive for in a playful setting regarding competencies such as problem solving and mathematical reasoning more than a list of specific mathematical knowledge, concepts and transformations that must be achieved and measured (for more information about preschool in Sweden, see Sumpter \& Hedefalk, 2015). 


\section{Background}

In the present paper, the focus will be on emotions. For definitions of other theoretical constructs in the affective perspective such as beliefs and attitudes, see for instance Philipp (2007) or Hannula (2012). An emotion is an affective reaction (Hannula, 2006), determining interest, willingness, and persistence (Dogan, 2010). Previously, emotions have been viewed based on the stability of the affective response, but in a framework in mathematics education proposed by Hannula (2012), there is instead a division between affect in state aspect or trait aspect. This means that we separate between an individual's reported feeling as it happens (state) from the tendency to feel something. Even though emotions in Hannula's (2012) framework are divided in social, psychological and physiological dimensions, the word 'emotion' is used independent if we talk about social positioning or a physiological response. In general emotion research, some researchers solve this by using two concepts, 'emotions' and 'feelings', to mark some sort of division (e.g. Goldie, 2002; Prinz, 2005; Whiting, 2011). Such a distinction would allow us talk about how the individual experience emotions and separate between different bodily reactions compared with different reports about how individuals express that they feel about something. Emotions would then involve both bodily feeling and feeling towards where the first one is sensations in the body and the latter an expressed emotion directed towards an object where the object can be 'a thing or a person, a state of affairs, or an action or event' (Goldie, 2002, p. 241). 'Feeling towards' is therefore a conscious experience that could be self-reported (Prinz, 2005). In this present paper, the focus is on emotional directions, which could be considered a synonym to 'feelings towards' (Goldie, 2002). It is about individuals' self-reports of how they emotionally experience an object, here mathematics. It is part of many other affective concepts such as emotional attitudes (c.f. Benz, 2012) or attitudes (c.f. Wilkins, 2002), beliefs (c.f. Lee \& Ginsburg, 2007) and confidence (Copley, 2004). When comparing it with theoretical concepts such as mathematical identity or teachers' professional identity, it shares the idea of a social construction such as this is what respondents report, positioning themselves in relation to the questions posed (c.f. Kaasila, Hannula \& Laine, 2012; Hermans, 1996; Lutovac \& Kaasila, 2018). Emotional directions towards mathematics could then be a part of teachers' expressed orientation towards their work (c.f. Beijaard, Meijer \& Verloop, 2004; Collopy, 2003; Karaolis \& Philippou, 2019).

Although emotions play an important role in learning and teaching, there are only a few studies looking at preschool educators' feelings towards mathematics (Benz, 2012; Chen, McCray, Adams \& Leow, 2014). Benz (2012) has studied German kindergarten professionals' attitudes towards mathematics in kindergarten including emotions. When asked to describe their feeling towards mathematics, the most common adjectives were useful (63\%), important (59\%), challenging (52\%), interesting (40\%) and confusing (35\%). In Benz's (2012) study, useful and important were thought of as neutral, challenging and interesting positive and confusing negative. Another study from Germany focusing on preschool teachers concluded that the teachers did not show negative attitudes towards mathematics in general (Anders \& Rossbach, 2015). In conclusion, research on German educators working with children age 1-5 indicates positive emotional directions towards mathematics, which is opposite what the general picture signal (Ginsburg et al., 2008). 
Looking at correlations, there is research showing that there is a connection between the attitudes towards mathematics and the age of the teachers, where younger teachers are more reluctant to the subject compared with older ones (e.g. Thiel, 2010). Similar results were reported by Thiel and Jenssen (2018) in their study of prospective teachers in Norway: older teacher students and part-time students with work-life experience from preschools expressed that they were less anxious about mathematics. This could be a result of 'the more experience, the more you know', and that with increased knowledge the positive feelings increase. Such process could also involve confidence and as stated earlier, preschool teachers are often seen as lacking confidence (Copley, 2004). However, when participating in an in-service training, Australian preschool educators expressed more confidence in communicating mathematics with increased knowledge in mathematics and mathematics education (Perry \& MacDonald, 2015). Similar results were found in a study of how teacher perceive their own attitudes after participating in a mathematics education programme and where the participants were more positive towards mathematics after education (Hourigan, Leavy \& Carroll, 2016). Increased knowledge appears to affect the individual's emotional direction towards a more positive one.

The perceived amount of content knowledge could also be a factor. Many Swedish preschool educators feel uncertain about how to work with mathematics and the conclusion was that this was due to lack of knowledge (Sheridan, 2009). When talking about mathematics, $36.6 \%$ say that they do not have enough mathematical knowledge, which could be compared with language (Swedish) and $17.9 \%$ of the educators. In the written comments, they express a wish to have more education in mathematics. Similar results are reported in a study looking at US pre-kindergarten teachers' beliefs where some of them also expressed that they felt, especially compared with literacy, that their attitude towards mathematics was a bit careless (Lee \& Ginsburg, 2007). The results also indicated that preschool mathematics teaching only develops with more awareness. This is a similar conclusion found in a study of Dutch teacher's, grade 2-4 (ages 5-8) and their epistemology and the monitoring of mathematical thinking (van Oers, 2002). In addition, studies report that upper elementary teachers have more positive attitudes compared with primary teachers (Wilkins, 2002) and primary teachers with education have a more positive view of themselves and their ability to teach mathematics compared with those without education (Karaolis \& Philippou, 2019). In sum, several studies from different countries indicate that there is a link between age/experience or perceived content knowledge and expressed feelings or attitudes.

Using these results as a backdrop, a possible hypothesis is that with more education in a subject, the more positive emotional direction you express towards the subject. This hypothesis is in line with studies reporting positive changes in early childhood teacher students' emotional directions after participating in courses in mathematics/ mathematics education (Hooks \& Duarte, 2005). These changes included expressing confidence to teach mathematics to 4-year olds.

\section{Methods}

In order to study preschool educators' expressed feelings towards mathematics, a questionnaire was made consisting of 10 questions including four background 
questions: (1) gender, (2) education, (3) years in profession and (4a) age of children in preschool group and (4b) number of children in preschool group. The question, besides background questions, that will be treated here is (item 5) how would you describe your relationship (including feelings) towards mathematics. This question aims to capture the preschool educators' expressed emotional direction towards mathematics. It should be stressed that in the Swedish language, there is no separation between feelings and emotions but instead uses the same word, 'känslor'. The data generated consists of what the respondents decide to self-report, allowing both retrospective explanations (c.f. Kaasila et al., 2012; Larsen, 2015; Lutovac \& Kaasila, 2018) but also tapping in to questions such as 'Who am I as a teacher now' (c.f. Karaolis \& Philippou, 2019).

A pilot study was made to test the instrument and the results indicated that most of the preschool educators were positive towards mathematics (Sumpter, 2015). Even though the word 'feelings' were mentioned in brackets, all respondents participating in the pilot study gave answers describing feelings, and the conclusion was that the phrasing 'your relationship (including feelings)' was enough to evoke responses describing emotional direction towards the subject. The word 'mathematics' is used as a general term meaning it was free for the respondents to interpret what mathematics could encompass. The reason for doing so was that the aim of this study is not to study feelings towards anything specific such as experiences from previous schooling or mathematics as a tool in society. Also, mathematics was used as a general term in previous research (e.g. Benz, 2012; Sheridan, 2009) so to allow comparisons, the same phrasing was used. (The other five items were about what type of mathematics they were doing with the children and about the curriculum.)

The data was collected in six cohorts (municipals): two in south of Sweden (one city and one rural town), two in mid-Sweden (one city and one rural town) and two north of Sweden (one bigger town and one rural village). The cohorts were chosen based on geography and size, but the preschools in each cohort were randomly picked. In each cohort, 3-7 preschools participated. In total, 25 preschools partook; all of them had children between 1-5 years old. Most of the preschools divided the children into different sections based on age. The most common division was younger children (1-3 years old) and older children (3-5 years old), but a few preschools had a three-step system. In all, 254 questionnaires were sent out based on rough estimations of number of staff made by the heads of the preschools, of which 157 preschool educators replied, 149 females and 8 males. The response rate was then, using the estimated numbers, $62 \%$. However, the response rate between the preschools varied a lot, between 13 and $100 \%$, where the main argument was absence such as sick leave and parental leave. It should be noted that there are no differences in the type of work that the different respondents are doing. One limitation with all self-reports studies is the wish to answer 'political correct' (Karaolis \& Philippou, 2019). Here, it was addressed by sending the questionnaire with a letter explaining the purpose of the study and also emphasising that there could be no wrong answers. Also, all the responses were given anonymously and coded before the analysis process following the ethics guidelines provided by the Swedish Research Council. The replies to item 5, besides no answers, varied between one word (e.g. 'good' or 'horrible') to long responses that covered both front and backside of the paper.

As a first tool to systemise the data, we use content analysis. The purpose is to extract desired information from a dataset by working systematically in order to 
identify specified characteristics (Smith, 2000). The aim is to reduce a larger body of material, 157 written responses, into categories and then add additional descriptive statistical information such as frequencies and lastly perform statistical analysis. You can either have an inductive approach (generating categories) or deductive approach (using already existing categories). Here, we have primarily used a deductive approach. We categorised the responses to the questionnaire using existing disjointed categories generated from the pilot study (Sumpter, 2015): positive (e.g. good), negative (e.g. I hate it and always have) and mixed feelings (i.e. expressing both positive and negative). A fourth category, neutral, was added based on Benz's (2012) study. It consisted of responses either explicitly saying 'I'm neutral' or using words containing neither negative nor positive connotations (e.g. something I use). The coding for each category was compared with the adjectives used in Benz (2012). No answer was marked as NA. There is no division whether the feelings are actually experienced when responding to the questionnaire (state aspect) or seen as sign of an emotional trait; the unit of analysis is 'expressed emotional directions'.

We tested two hypotheses. First, we tested the null hypothesis that the degree of positive or negative feelings did not depend on type of education, against the alternative hypothesis that those educators with less education were less positive (c.f. Karaolis \& Philippou, 2019). To perform this test, we first calculated the overall proportion (independent of type of education) of educators describing negative feelings. Then, for each of the four education types (upper secondary school, preschool teacher, primary school teacher and other university education) (no education listed, i.e. NA, was not part of this test), we looked at the number of educators with negative feelings and tested whether it was significantly different than the overall proportion with negative feelings. Specifically, under this null hypothesis, we have a sign test for each category, i.e. the observed number is binomially distributed with parameters $n=$ number of individuals with education type and $p=$ overall proportion of negative feelings. The $P$ value for the sign test is then the probability of obtaining greater than or equal to the observed number of individuals with negative feelings under this null hypothesis. The second null hypothesis was a variation of 'the more knowledge - the more positive', but here knowledge from teaching experience: that the number of stated years in the profession did not affect emotional directions (c.f. Thiel \& Jenssen, 2018). We tested this against the alternative hypothesis that with more years in the profession, the more positive emotional directions preschool educators will express. To make the test, we performed binary logistic regression with positive or negative as the response variable and years in the profession as the independent variable.

We also performed a qualitative analysis of the responses. The written comments were analysed using two categories identified in the pilot study: static view (e.g. I have always felt this way) or dynamic view (e.g. I used to feel this, but now I feel in another way). This generated a subset of the data where 40 respondents expressed either a static view or a dynamic view. Each category was then reviewed using content analysis looking for internal dimensions of the subset of data. This analysis was made with an inductive approach since the pilot study did not address this issue and no previous research that has targeted such properties was found. The aim for the analysis was to identify variations such as differences and similarities. The first division in this analysis was the different directions of the changes such as more negative to less negative (e.g. I do not like mathematics, but it used to be even worse) or negative to positive (e.g. It 
used to be bad, but now it is good). Within the different subcategories, the next phase of coding were patterns regarding the attributed causes to emotional directions, either now (e.g. I used to feel this, but now I'm feeling this because of X) or in the past (e.g. I used to feel this because of Y, but now I feel this), and the different reasons for changes such as participation in various forms of education or other changes influencing the work e.g., a new curriculum.

\section{Results}

In the presentation of data, responses are marked with square brackets with letter as a code for different preschools and number for different respondents within the preschool. Spelling mistakes are corrected since the focus is on the content. All respondents answered the question 'How would you describe your relationship (including emotions) towards mathematics?' except for one (here marked with NA). The results are shown in Table 1.

As we can see in Table 1, the majority of the preschool educators (64\%) express a positive relationship towards mathematics. The division between male and female are only in the presentation of data. No statistical analysis was made to see if there are any significant differences between male and female since the number of responses from male educators was too low.

\section{Different Education}

The data was categorised using background information of stated education. The results are presented in Table 2 with frequencies and percentages in brackets.

Two-thirds of the respondents have a university degree. An example of 'other university education' is a graduate economist (E5). Most educators are preschool teachers $(53 \%)$. None of the respondents have stated that they have less than upper secondary schooling; however, four respondents did not reply at all. Using Table 2, we then tested the first null hypothesis: that the degree of positive or negative feelings did not depend on type of education, against the alternative hypothesis that those educators with less education were less positive. This test was repeated using positive against neutral or negative, and positive or neutral against negative, see Table 3:

As shown in Table 3, the null hypothesis was not rejected for any of the education levels. The majority of the preschool educators participating in this study expressed positive emotional directions towards mathematics; this is independent of education.

Table 1 Preschool educators' feelings towards mathematics, $n(\%)$

\begin{tabular}{lcccccc}
\hline Feelings & Positive & Neutral & Negative & Mix & NA & Total \\
\hline All respondents & $100(64 \%)$ & $21(13 \%)$ & $21(13 \%)$ & $14(9 \%)$ & $1(0.6 \%)$ & $157(100 \%)$ \\
Female & $96(61 \%)$ & $19(12 \%)$ & $21(13 \%)$ & $13(8 \%)$ & $0(0 \%)$ & $149(95 \%)$ \\
Male & $4(3 \%)$ & $2(1 \%)$ & $0(0 \%)$ & $1(0.6 \%)$ & $1(0.6 \%)$ & $8(5 \%)$ \\
\hline
\end{tabular}

$N A$, no answer 
Table 2 Preschool educators' feelings towards mathematics, $n(\%)$

\begin{tabular}{lcccccc}
\hline Education & Positive & Neutral & Negative & Mix & NA & Total \\
\hline Upper secondary school & $30(19 \%)$ & $9(6 \%)$ & $6(4 \%)$ & $3(2 \%)$ & $1(0.6 \%)$ & $49(31 \%)$ \\
Preschool teacher & $56(36 \%)$ & $9(6 \%)$ & $12(8 \%)$ & $6(4 \%)$ & $0(0 \%)$ & $83(53 \%)$ \\
Primary school teacher & $7(4 \%)$ & $3(2 \%)$ & $2(1 \%)$ & $5(3 \%)$ & $0(0 \%)$ & $17(11 \%)$ \\
Other university education & $4(3 \%)$ & $0(0 \%)$ & $0(0 \%)$ & $0(\%)$ & $0(0 \%)$ & $4(3 \%)$ \\
NA & $3(2 \%)$ & $0(0 \%)$ & $1(0.6 \%)$ & $0(0 \%)$ & $0(0 \%)$ & $4(3 \%)$ \\
Total & $100(64 \%)$ & $21(13 \%)$ & $21(13 \%)$ & $14(9 \%)$ & $1(0.6 \%)$ & $157(100 \%)$ \\
\hline
\end{tabular}

\section{Years of Work Experience}

The second factor we wanted to study was the number of stated years of work experience. The division into different age categories in Table 4 are only for presentation of the data:

The number of years of work experience ranged from 1 to 45 years. The null hypothesis proposed was that the number of stated years in the profession did not affect emotional directions, and it was tested against the alternative hypothesis that more positive emotional directions preschool educators will express. The test was a binary logistic regression meaning we used the questionnaire responses coded as positive or negative as the response variable and years in the profession as the independent variable. The logistic regression analysis gave the following results (see Table 5).

According to results presented in Table 5, the number of years of work experience do not significantly correlate with expressed feelings such that 'the more years, the more positive' is true. In order to check that this result was not due to the omission of the 'neutral' feelings, we repeated the logistic regression this time with a 'positive' class and a combined 'negative/neutral' class. Number of years still did not have an impact on feeling $(P=0.22)$.

\section{Static View Dynamic View}

As a third analysis, we focus on the subset of data expressing either a static view ( $n=$ $15 ; 10 \%$ of total respondents) or a dynamic view ( $n=25 ; 16 \%$ of total respondents)

Table 3 Result sign test, preschool educators' feelings towards mathematics

\begin{tabular}{llll}
\hline Education/ $P$ value & $\begin{array}{l}\text { Positive } \\
\text { vs negative }\end{array}$ & $\begin{array}{l}\text { Positive } \\
\text { vs neutral or negative }\end{array}$ & $\begin{array}{l}\text { Positive or neutral } \\
\text { vs negative }\end{array}$ \\
\hline Upper secondary school & 0.42 & 0.24 & 0.49 \\
Preschool teacher & 0.38 & 0.63 & 0.31 \\
Primary school teacher & 0.19 & 0.11 & 0.25 \\
Other university education & 0.53 & 0.76 & 0.47 \\
Total & & & 0.15 \\
Overall probability $(p)$ & 0.17 & 0.30 & \\
\hline
\end{tabular}


Table 4 Preschool educators' emotional direction towards mathematics by age, $n(\%)$

\begin{tabular}{lccclll}
\hline Years of work experience & Positive & Neutral & Negative & Mix & NA & Total \\
\hline $0-9$ & $24(\%)$ & $7(4 \%)$ & $5(3 \%)$ & $6(4 \%)$ & $1(0.6 \%)$ & $43(27 \%)$ \\
$10-19$ & $21(13 \%)$ & $4(3 \%)$ & $6(4 \%)$ & $2(1 \%)$ & $0(0 \%)$ & $33(21 \%)$ \\
$20-29$ & $25(16 \%)$ & $5(3 \%)$ & $7(4 \%)$ & $3(2 \%)$ & $0(0 \%)$ & $40(25 \%)$ \\
$30-39$ & $23(15 \%)$ & $3(2 \%)$ & $3(2 \%)$ & $2(1 \%)$ & $0(0 \%)$ & $31(20 \%)$ \\
$40-49$ & $5(3 \%)$ & $1(0.6 \%)$ & $0(0 \%)$ & $1(0.6 \%)$ & $0(0 \%)$ & $7(4 \%)$ \\
NA & $2(1 \%)$ & $1(0.6 \%)$ & $0(0 \%)$ & $0(0 \%)$ & $0(0 \%)$ & $3(2 \%)$ \\
Total & $100(64 \%)$ & $21(13 \%)$ & $21(13 \%)$ & $14(9 \%)$ & $1(0.6 \%)$ & $157(100 \%)$ \\
\hline
\end{tabular}

towards mathematics. The 40 responses were first organised in the following way (see Table 6).

With respect to the static view, the majority of respondents stated that they were positive and have always been positive. The respondents have different type of educational background: upper secondary schooling, preschool teacher programme and primary teacher programme. In the responses, we can read adjectives such as fun, challenging, exciting, interesting and verbs such as like and love. These three responses illustrate this positive static view:

I have never experienced mathematics as dull or difficult. I have always understood and have had a positive view and great interest for math [G4]; I like mathematics and have always done so. Thinks it is fun with problem solving. Thinks it is fun and challenging to learn something new and sit and figure out how it works, and when you learnt it, it often feels easy and incredible logical [W3]; My relationship to mathematics is good. Liked mathematics a lot in school, especially at primary level. Struggled with mathematics at lower secondary level, but I liked it anyway [O7].

These responses illustrate different reasons why the respondents like mathematics and have always liked mathematics. In the first response, 'to understand' is one of the explanations provided. Similar reasoning is given in the second selected quote when stating that "it often feels easy". Problem solving is emphasised, in particular the 'struggle' to figure something out. The third response show that even though schooling can be tough, the positive feelings towards mathematics prevail.

Table 5 Result of binary logistic regression, feelings towards and years of work experience

\begin{tabular}{lllll}
\hline & Estimate & SE & $z$ value & $P$ value \\
\hline Intercept & 1.2 & 0.44 & 2.6 & 0.0082 \\
Numbers of years & 0.019 & 0.020 & 0.93 & 0.35 \\
\hline
\end{tabular}

Negative is classified as 0 and positive as 1 
Table 6 Preschool educators' emotional direction towards mathematics: static or dynamic view, $n(\%)$

\begin{tabular}{llllll}
\hline & Positive & Neutral & Negative & Mix & Total \\
\hline Static view & $13(87 \%)$ & $0(0 \%)$ & $2(13 \%)$ & $0(0 \%)$ & $15(100 \%)$ \\
Dynamic view & $16(64 \%)$ & $3(12 \%)$ & $2(8 \%)$ & $4(16 \%)$ & $25(100 \%)$ \\
\hline
\end{tabular}

Two responses describe a negative static view. In the written comments, we see different reasons:

Not my area, from my own experiences I have always found it difficult and hard [U3]; Do really not like math. Had a terrible math teacher at upper primary level. Mainly just angry if you didn't understand. So, then my interest for mathematics died [N2].

In the first response, for this preschool educator (with primary teacher education) mathematics has always been thought of as 'difficult and hard'. In the second response, particular experiences and interactions with a mathematics teacher in grade 4-6 are considered the reason to the negative feelings. This response was given by a preschool educator with upper secondary schooling but no university education. To summarise the static view, strong feelings (most often positive) towards the subject are communicated in the written responses.

Regarding a dynamic view, the most common transfer $(n=16)$ where from negative feelings to positive feelings towards mathematics. In the responses, several different explanations where given. One reason is the preschool teacher education in itself, here illustrated by one preschool teacher:

Have previously associated mathematics with anxiety and difficulties. In relation to/During my education, I see math everywhere in our everyday life and it can be both fun and creative [U2].

Here, it was the preschool teacher education that created the shift and the feelings went from 'anxiety' to 'fun and creative'. Some educators talk about changes due to participation in different courses as part of in-service training. One of these courses was an in-service teaching training provided by the school agency and executed by different universities, 'Förskolelyftet':

Have been very inspired of mathematics since I did Förskolelyftet and are now viewing mathematics with completely new eyes. Think it is fun which I didn't used to think before, mainly difficult then. [C1]; Thoughts immediately goes back to days in school, but I have participated in Förskolelyftet and thereby got a different view and feelings towards "mathematics" [F5].

For these two teachers, it wasn't previous education that changed their emotional directions but this particular in-service training. Another respondent mentions a specific 
course taken as part of a post-secondary education. This course was given by a university. (The name of the course has been marked by $\mathrm{X}$ so it cannot be identified.)

Since I have recently studied X at the university, I have developed a new thinking in my relationship with mathematic. A very good course! [T1].

Other further education, such as different seminars and lectures, is also mentioned as a cause for a positive shift:

In the beginning when I heard that we should work so much with mathematics I had feeling back to when I was young and didn't like mathematics at all in school. Now I have been to different lectures about mathematics in preschool [it] feels fun and inspiring. We "breaks" it down to the children's level... [M2].

In this response, there is a link between change of emotional direction, further education and the work with mathematics in preschool. A similar reasoning, although without any explanations to what caused the change, was given by this preschool teacher:

Have changed my attitude since school days and now thinks it is interesting and challenging. (Before it was horror and anxiety) [M6]

These two responses indicate an interplay between affect and present work as a teacher. Other responses which were more explicit about the change over the years:

Good. Has become better over the years. Before, I always wanted to know why you should do in a certain way, which school had difficulty [with] to explain. Always liked to work in a practical way in order to understand which I [now] bring to my work. Make visible for the children. [F3]

Over the years, in particular comparing with their own days in school, the feelings towards mathematics have become more positive. Another comparison regarding personal experiences from their own schooling days is that the nature of school mathematics has changed:

In school, I was a typical "average". Neither easy nor difficult. But over the years I [now] know that mathematics is so much more. For instance, problem solving that it wasn't so much of when I went to school. [Then] It was solving tasks page up and down. [L3]; Nowadays, thinks mathematics is fun, try to get mathematics in [to the day] in different playful ways and different types of mathematics e.g. sorting, statistics, geometry and number sense. [V6].

These responses indicate that there is a link between positive emotional directions and the type of mathematics that they work with today, mathematics that differ from their own schooling, but also their work to 'break down' the mathematics to the children. 
Four responses described mixed feelings towards mathematics. One quote is chosen to illustrate this category:

Both easy and hard. I'm not so technical disposed so it hasn't been [my] number 1 priority. But zestful in school. I have still educated myself in mathematics but have been missing the pedagogical discussion about [it]. But since the new version of the curriculum better. [X2]

This educator (with upper secondary schooling) stresses the revision of the curriculum as a reason for positive change, although still mixed feelings. Two responses mention a shift in a positive direction however still negative feelings towards mathematics, here it is shown by the following response:

Not that I have used and think it is important to use but it comes more and more. [E6]

Even though there has been a shift (and still is), mathematics is still regarded as not important. Three educators expressed neutral feelings towards mathematics but also a transfer from negative feelings to neutral:

Didn't like the math that was [in school] when I went to school, but have nothing against the type of math we are working with in preschool. [H6].

The difference in expressed emotional direction is, according to the respondent, more due to the type of mathematics that is in focus more than, for instance, teacher training or in-service training.

\section{Discussion}

Given that preschool educator's affective world is a research area that we do not know enough about (Benz, 2012) and the awareness that preschool teachers play an important role (Einarsdottir, 2003; Ngan Ng et al., 2003), this paper adds to the descriptive knowledge regarding preschool educators' expressed emotional directions towards mathematics. This is helpful when a profession is under transformation since it not only evaluates the ongoing process but also identify potential needs or obstacles (c.f. Karaolis \& Philippou, 2019; Sheridan et al., 2011; Waller et al., 2010). The main result from this study is that the majority of the respondents express positive emotional directions towards mathematics: two-thirds of the preschool educators, $64 \%$, used only positive feelings when describing their relationship towards mathematics. The results are in line with previous research (e.g. Anders \& Rossbach, 2015), or to paraphrase Benz (2012): compared with the reputation, preschool educators' expressed feelings about mathematics are more positive. It goes against the traditional assumption that preschool teachers do not like mathematics (Ginsburg et al., 2008). This is an important result, especially regarding the concern that was raised by Ball (1990) or the report that children's attitudes, including feelings, towards mathematics are influenced by the teachers through child-teacher interactions (Gunderson et al., 2012). The conclusion is then 
that the starting point for teaching mathematics appears to be relatively good (c.f. Beilock et al., 2010; Wilkins, 2008), something that should be taken into account when planning for in-service education and other interventions (c.f. Thiel \& Jenssen, 2018).

Furthermore, we tested two hypotheses. The first null hypothesis was that the degree of positive or negative feelings did not depend on type of education, and it was tested against the alternative hypothesis that those educators with less education were less positive. The results were not significant. The preschool educators participating in this study were positive independent of education. The second null hypothesis was a variation of the first one but instead of education, we focus on the number of years in the profession not affecting emotional directions. It was tested against the alternative hypothesis that with more years in the profession, more positive emotional directions preschool educators will express. These results were also not significant. It could be tempting to conclude that previous research reporting about 'more education, more positive' and 'more years in profession, more positive' is not true for Swedish preschool educators, but such conclusions cannot be drawn from this part of the analysis. When so many respondents are positive from the start, the differences regarding different factors are bound to be small; a result that could inform other researchers wanting to study preschool educators' expressed emotions only using quantitative measures. Also, the question was not posed with these changes in mind explicitly, but more to capture preschool educators' main emotional directions. This is of course a limitation when focusing on changes. This could be compared with Kaasila et al.'s (2012) conclusion when studying mathematical identity and emotions as social text: individuals have different identities that appear in different contexts and the results is then in relation to the methods of the study.

However, within these factors, small changes can be of importance especially regarding that they were expressed without direct questions as seen in the responses expressing a shift in their emotional direction towards mathematics. All responses in this subset described a positive change. The content analysis showed that the main reasons for changing stated by the respondents was more knowledge, more experience and/or how (pre)school mathematics has changed, including the new revised curriculum. A few of the respondents talked about a shift in emotional directions (from negative to positive) due to either further education or change of nature of mathematics (e.g. more problem solving) in relation to their profession today. These results support previous research reporting similar shifts (e.g. Hooks \& Duarte, 2005; Thiel, 2010). For some of the respondents who talks about a change due to more teaching experience or more education, the positioning of themselves as 'positive to mathematics' appears to be a part of their teacher identity and their profession (c.f. Beijaard et al., 2004; Kaasila et al., 2012; Karaolis \& Philippou, 2019; Lutovac \& Kaasila, 2018). Adding the results from Sheridan (2009), where preschool educators expressed a wish of more knowledge in mathematics and mathematics education, a plausible conclusion and a possible implication relevant to both teacher education and policy makers is that if preschool educators are given the chance and possibility to continue to educate themselves in mathematics, an even larger number will express positive feelings towards mathematics. This is similar to previous findings about shifts in emotion (e.g. Dogan, 2010).

Another result from this present study is regarding the respondents who expressed a static view, i.e. emotional directions have always been in a specific way. The existence 
of such view was indicated in a pilot study (Sumpter, 2015). In this present study, the written responses signal strong feelings towards mathematics where the majority are positive. Here, we cannot make any more specific conclusions about why some preschool educators report that they love/hate mathematics (and always has). However, having Benz (2012) conclusion in mind, that we should not underestimate when onethird of kindergarten teachers find mathematics confusing, a similar approach could be employed regarding the $21 \%$ who in the present study expressed negative feelings when describing their relationship with mathematics, and in particular the small subset who state that they prevail negative emotional directions independent of education, years of experience, change of work settings, etc. Considering that this is an area we know little about (Benz, 2012; Chen et al., 2014), we suggest this as a subject for further research.

Funding Information Open access funding provided by Stockholm University.

Open Access This article is distributed under the terms of the Creative Commons Attribution 4.0 International License (http://creativecommons.org/licenses/by/4.0/), which permits unrestricted use, distribution, and reproduction in any medium, provided you give appropriate credit to the original author(s) and the source, provide a link to the Creative Commons license, and indicate if changes were made.

\section{References}

Anders, Y., \& Rossbach, H.-G. (2015). Preschool teachers' sensitivity to mathematics in children's play: The influence of math-related school experiences, emotional attitudes, and pedagogical beliefs. Journal of Research in Childhood Education, 29(3), 305-322.

Ball, D. L. (1990). Prospective elementary and secondary teachers' understanding of division. Journal for Research in Mathematics Education, 21, 132-144.

Beijaard, D., Meijer, P. C., \& Verloop, N. (2004). Reconsidering research on teachers' professional identity. Teaching and Teacher Education, 20(2), 107-128.

Beilock, S. L., Gunderson, E. A., Ramirez, G., \& Levine, S. C. (2010). Female teachers' math anxiety affects girls' math achievement. Proceedings of the National Academy of Sciences of the United States of America, 107, 1860-1863.

Benz, C. (2012). Maths is not dangerous - attitudes of people working in German kindergarten about mathematics in kindergarten. European Early Childhood Education Research Journal, 20(2), 249-261.

Chen, J. Q., McCray, J., Adams, M., \& Leow, C. (2014). A survey study of early childhood teachers' beliefs and confidence about teaching early math. Early Childhood Education Journal, 42(6), 367-377.

Collopy, R. (2003). Curriculum materials as a professional development tool: How a mathematics textbook affected two teachers' learning. Elementary School Journal, 103, 287-311.

Copley, J. V. (2004). The early childhood mathematics collaborative: A professional development model to communicate and implement the standards. In D. H. Clements \& J. Sarama (Eds.), Engaging young children in mathematics: Standards for early mathematics education (pp. 401-414). Mahwah, NJ: Lawrence Erlbaum.

Dogan, H. (2010). Emotion, confidence, perception and expectation case of mathematics. International Journal of Science and Mathematics Education, 10, 49-69.

Einarsdottir, J. (2003). Principles underlying the work of Icelandic preschool teachers. European Early Childhood Education Research Journal, 11(1), 39-53.

Ginsburg, H. P., Lee, J. S., \& Boyd, J. S. (2008). Mathematics education for young children: What it is and how to promote it. Society for Research in Child Development, social policy report, vol. 22(1).

Goldie, P. (2002). Emotions, feelings and intentionality. Phenomenology and the Cognitive Sciences, $1,235-254$

Greenes, C. (2004). Ready to learn: Developing young children's mathematical powers. In J. Copley (Ed.), Mathematics in the early years (3rd ed., pp. 39-47). Reston, VA: NCTM. 
Gunderson, E. A., Ramirez, G., Levine, S. C., \& Beilock, S. L. (2012). The role of parents and teachers in the development of gender-related math attitudes. Sex Roles, 66, 153-166.

Hannula, M. S. (2006). Affect in mathematical thinking and learning: Towards integration of emotion, motivation and cognition. In J. Maasz \& W. Schloeglmann (Eds.), New mathematics education research and practice (pp. 209-232). Rotterdam: Sense Publishers.

Hannula, M. S. (2012). Exploring new dimensions of mathematics-related affect: Embodied and social theories. Research in Mathematics Education, 14(2), 137-161.

Hermans, H. J. M. (1996). Voicing the self: From information processing to dialogical interchange. Psychological Bulletin, 119(1), 31-50.

Hooks, L., \& Duarte, V. (2005). Can 4-yr olds really do math? Using the project approach with pre service teachers. Journal of Early Childhood Teacher Education, 25(2), 185-192.

Hourigan, M., Leavy, A. M., \& Carroll, C. (2016). 'Come in with an open mind': Changing attitudes towards mathematics in primary teacher education. Educational Research, 58, 319-346. https://doi.org/10.1080 /00131881.2016.1200340.

Kaasila, R., Hannula, M. S., \& Laine, A. (2012). "My personal relationship towards mathematics has necessarily not changed but...” Analyzing pre-service teachers' mathematical identity talk. International Journal of Science and Mathematics Education, 10(4), 975-995.

Karaolis, A., \& Philippou, G. N. (2019). Teachers’ professional identity. In M. S. Hannula, G. C. Leder, F. Morselli, M. Vollstedt, \& Q. Zhang (Eds.), Affect and mathematics education (pp. 397-417). Cham: Springer.

Larsen, J. (2015). Attitude and motivation in the lives of mathematics teachers: A narrative case study. In L. Sumpter (Ed.), Current state of research on mathematical beliefs XX (pp. 127-137). Umeå: Umeå Print och Media.

Leavy, A. M., Hourigan, M., \& Carroll, C. (2017). Exploring the impact of reform mathematics on entry-level pre-service primary teachers attitudes towards mathematics. International Journal of Science and Mathematics Education, 15(3), 509-526. https://doi.org/10.1007/s10763-015-9699-1.

Lee, S. L., \& Ginsburg, H. P. (2007). What is appropriate mathematics education for four year-olds? Prekindergarten teachers' belief. Journal of Early Childhood Research, 5(1), 2-31.

Levine, S., Whealton Suriyakham, L., Rowe, M. L., Huttenlocher, J., \& Gunderson, E. A. (2010). What counts in the development of young children's number knowledge? Developmental Psychology, 46(5), 13091319.

Lutovac, S. \& Kaasila, R. (2018). Future directions in research on mathematics-related teacher identity. International Journal of Science and Mathematics Education, 16(4), 759-776. https://doi.org/10.1007 /s10763-017-9796-4.

Ngan Ng, S., Lopez-Real, F., \& Rao, N. (2003). Early mathematics teaching: The relationship between teacher's belief and classroom practices. In N. A. Pateman, B. J. Dougherty, \& J. Zilliox (Eds.), Proc. 27th conference of the international group for the psychology of mathematics education (pp. 213-220). Honolulu: PME.

Perry, B., \& MacDonald, A. (2015). Educators' expectations and aspirations around young children's mathematical knowledge. Professional Development in Education, 41(2), 366-381.

Philipp, R. (2007). Mathematics teachers' beliefs and affect. In I. F. Lester (Ed.), Second handbook of research on mathematics teaching and learning (pp. 257-315). Charlotte, NC: NCTM, Information Age Publishing.

Prinz, J. J. (2005). Are emotions feelings? Journal of Consciousness Studies, 12(8-10), 9-25.

Sheridan, S. (2009). Lärares och föräldrars syn på förskolan [Teachers and parents' view on preschool]. In S. Sheridan, I. P. Samuelsson, \& E. Johansson (Eds.), Barns tidiga lärande [Children's early learning] (pp. 93-124). Gothenburg: Gothenburg University.

Sheridan, S., Williams, P., Sandberg, A., \& Vuorinen, T. (2011). Preschool teaching in Sweden - A profession in change. Educational Research, 53(4), 415-437.

Smith, E. R. (2000). Research design. In H. T. Reis \& C. M. Judd (Eds.), Handbook of research methods in social and personality psychology (pp. 17-39). New York: Cambridge University Press.

Spodek, B. (1987). Thought processes underlying preschool teachers' classroom decisions. Early Child Care and Education, 29(2), 197-208.

Stipek, D. J., \& Byler, P. (1997). Early childhood teachers: Do they practice what they preach? Early Childhood Research Quarterly, 12, 305-325.

Sumpter, L. (2015). Preschool teachers' conceptions about mathematics. In C. Bernack- Schüler, R. Erens, T. Leuders \& A. Eichler (Eds.), Views and beliefs in mathematics education: Results of the 19th MAVI Conference (pp. 55-66). Wiesbaden: Springer Spektrum. 
Sumpter, L. \& Hedefalk, M. (2015). Preschool children's collective mathematical reasoning during free outdoor play. The Journal of Mathematical Behavior, 39, 1-10.

Thiel, O. (2010). Teachers' attitudes towards mathematics in early childhood education. European Early Childhood Education Research Journal, 18(1), 105-115.

Thiel, O., \& Jenssen, L. (2018). Affective-motivational aspects of early childhood teacher students' knowledge about mathematics. European Early Childhood Education Research Journal, 26(4), 512-534.

van Oers, B. (2002). Teachers' epistemology and the monitoring of mathematical thinking in early years classrooms. European Early Childhood Education Research Journal, 10(2), 19-30.

Waller, T., Sandeseter, E. B. H., Wyver, S., Ärlemalm-Hagsér, E., \& Maynard, T. (2010). The dynamics of early childhood spaces: opportunities for outdoor play? European Early Childhood Education Research Journal, 18(4), 437-443.

Whiting, D. (2011). The feeling theory of emotion and the object-directed emotions. European Journal of Philosophy, 1, 281-303.

Wilkins, J. L. M. (2002). The impact of teachers' content knowledge and attitudes on instructional beliefs and practices. In D. S. Mewborn, P. Sztajn, D. Y. White, H. G. Wiegel, R. L. Bryant, \& K. Nooney (Eds.), Proceedings of the annual meeting of the North American Chapter of the International Group for the Psychology of Mathematics Education (pp. 1579-1587), Athens, GA: International Group for the Psychology of Mathematics Education. Available Oct 9th, 2015 at http://files.eric.ed. gov/fulltext/ED471775.pdf.

Wilkins, J. L. M. (2008). The relationship among elementary teachers' content knowledge, attitudes, beliefs, and practices. Journal of Mathematics Teacher Education, 11(2), 139-164. https://doi.org/10.1007 /s10857-007-9068-2. 